\title{
Chemical constituents and In vitro anticancer activity of Tiliacora triandra leaves
}

\author{
Surapong Rattana', Benjamart Cushnie ${ }^{2}$, Ladachart Taepongsorat ${ }^{3}$ and Methin Phadungkit ${ }^{4 *}$ \\ 'Faculty of Science, Mahasarakham University, Kantarawichai, Maha Sarakham-44150, Thailand. \\ 2,4Faculty of Pharmacy, Mahasarakham University, Kantarawichai, Maha Sarakham-44150, Thailand. \\ ${ }^{3}$ Faculty of Medicine, Mahasarakham University, Meuang, MahaSarakham-44000, Thailand.
}

\begin{abstract}
Introduction: Tiliacora triandra (F. Menispermaceae) is edible and is also known for medicinal values. The leaves are a popular flavoring in Southeast Asia, especially in the northeast of Thailand. The objectives of this study were to determine the major constituents of the leaves of $T$. trian$d r a$, and assess their anticancer activities against human cancer cell lines. Methods: The leaves were extracted by a soxhlet apparatus with petroleum ether, dichloromethane, ethyl acetate and water. Major constituents were then purified and identified using chromatographic procedures and various spectroscopic techniques. In vitro anticancer activity tests of $T$. triandra extracts were performed by resazurinmicroplate assay (REMA), and tested with 3 cell lines: oral cavity cancer (KB), lung cancer (NCI-H187) and breast cancer (MCF-7) cell lines. Results: The result indicated that the main compound of $T$. triandra leaves was oxoanolobine. The methanol extract showed the highest cytotoxic activity against lung cancer (NCl-H187) cell line whereas the water extract exhibited the highest activity against oral
\end{abstract}

cavity cancer $(\mathrm{KB})$ cell line. The $\mathrm{IC}_{50}$ of oxoanolobine against the $\mathrm{NCl}-\mathrm{H} 187$ cell line was $27.60 \pm 4.30 \mu \mathrm{g} / \mathrm{mL}$. Conclusion: $T$. triandra leaves contain oxoanolobine as the major constituent and have the potential of anticancer activity but are required to be investigated further.

Key words: In vitro anticancer activity, Oxoanolobine, Phytochemistry, Tiliacora triandra, Yanang

Address for correspondence:

Dr. Methin Phadungkit, Ph.D., Faculty of Pharmacy, Mahasarakham University, Mahasarakham, 44150 Thailand.

Phone no: +66 823074184

E-mail: phadang_p@hotmail.com

DOI : 10.5530/pj.2016.1.1

\section{INTRODUCTION}

Tiliacora triandra Diels (Menispermaceae) is a species of flowering plant native to Southeast Asia. This plant is widespread in the northeast of Thailand and Lao PDR. It is a climbing plant with deep green leaves and yellowish flowers. Their leaves are used particularly in many cuisines of the northeast of Thailand and Lao PDR, especially in traditional bamboo shoot soup. The leaves are often used in traditional Thai medicine as antipyretic and anticancer agents. ${ }^{1}$ Phytochemical study of its root revealed some bisbenzylisoquinoline alkaloids, including tiliacorine, tiliacorinine and nor-tiliacorinine A. ${ }^{2}$ Previous study demonstrated that plants containing bisbenzylisoquinoline alkaloids have been used in traditional medicine for the treatment cancer. ${ }^{3}$ Chemical analysis revealed that $T$. triandra possesses high levels of beta-carotene and minerals such as calcium and iron. ${ }^{4}$ The root extract is used for treatment of fever and malaria. ${ }^{5}$ The water extract does not cause acute or subchronic toxicities in either male or female rats. ${ }^{6}$

Cancer is the leading cause of death in developed countries and the second leading cause of death in developing countries. The most common cancers worldwide are lung cancer, breast cancer, large intestine cancer, stomach cancer and prostate cancer. ${ }^{7}$ Incidence and mortality rates for most cancers are increasing in several countries because of adoption of unhealthy lifestyles, such as smoking, physical inactivity and consumption of high calorie food. ${ }^{8}$ Nowadays, there has been huge attention towards natural products with their cancer prevention and therapeutic effectiveness. Evidence suggests that phytochemicals from fruits and vegetables may play an important role in reducing chronic disease risk including cancer. ${ }^{9,10}$

Despite the traditional claims of anticancer properties of T. triandra leaves was reported and there has been minimal investigation of chemical constituents and anticancer activity in T. triandra leaves. Therefore, objectives of this study were to investigate the chemical com- position and to test anticancer activity of its extracts and the isolated compounds against human cancer cell lines. The results of the current study demonstrate the potential of this plant in cancer prevention and treatment.

\section{MATERIALS AND METHODS}

\section{Preparation of plant extracts}

The plant sample (leaves) of T. triandra was collected from the Maha Sarakham province, Thailand and identified by the authors (Dr. Phadungkit M). The voucher specimens were deposited at Faculty of Pharmacy, Mahasarakham University, Thailand. The leaves were pulverized and sequentially extracted by a soxhlet apparatus using petroleum ether, dichloromethane, ethyl acetate and methanol. Some of the leaf powder was macerated in water for 7 days. The solvents were evaporated by a rotary evaporator, whereas the water extract was lyophilized by a freeze dryer. The crude extracts obtained were subjected to investigate the chemical constituent and to test anticancer activity.

\section{Isolation and Identification of chemical components}

The methanol extract was subjected to column chromatography using a glass column packed with silica gel Si-60 (Merck) and eluted with a stepwise gradient of hexane and dichloromethane mixtures $(100: 0 ; 90: 10 ; 80: 10 ; 70: 30 ; 60: 40 ; 50: 50 ; 30: 70 ; 20: 80 ; 0: 100)$ followed by a stepwise gradient of dichloromethane and methanol mixtures $(100: 0 ; 90: 10 ; 80: 10 ; 70: 30 ; 60: 40 ; 50: 50 ; 30: 70 ; 20: 80 ; 0: 100)$. Two hundred column fractions, each containing $50 \mathrm{~mL}$ were collected and combined according to their TLC profiles on Kiesegel $60 \mathrm{~F}_{254}$ precoated aluminium plates developed with dichloromethane/ethyl acetate/methanol/formic acid mixture (10:1:1:1). The enriched fraction 
Table 1: ${ }^{13} \mathrm{C}$ and ${ }^{1} \mathrm{H}$ NMR spectral data of the isolated compound in CD 0 OD

\begin{tabular}{ccc}
\hline Position & ${ }^{13} \mathrm{C}, \delta(\mathrm{ppm})$ & $1 \mathrm{H}, \delta(\mathrm{ppm})$ \\
\hline 4 & 104.6 & 7.195 \\
$\mathrm{O}_{2} \mathrm{CH}_{2}$ & 107.1 & 6.17 \\
7 & 121.84 & - \\
$2^{\prime}$ & 127.84 & 7.95 \\
$1^{\prime}$ & 130.59 & - \\
$6^{\prime}$ & 130.95 & 8.08 \\
$3^{\prime}$ & 131.87 & 8.80 \\
$2^{\prime}$ & 132.78 & - \\
$4^{\prime}$ & 133.90 & 7.56 \\
$1^{\prime}$ & 138.62 & 8.38 \\
$8^{\prime}$ & 140.24 & - \\
3 & 146.90 & - \\
$5^{\prime}$ & 157.80 & - \\
9 & 161.47 & - \\
6 & 164.29 & - \\
$5^{\prime}$ & 164.58 & - \\
$1^{\prime}$ & 182.16 & \\
\hline
\end{tabular}

(149-164) was evaporated using a rotary evaporator and was recrystallized from methanol to yield yellowish amorphous crystal. The isolated compound was identified by comparing their spectroscopic (IR, MS, $1 \mathrm{H}$ and ${ }^{13} \mathrm{C} \mathrm{NMR}$ ) data with those reported in the literature.

\section{In vitro anticancer assay}

In vitro anticancer activity tests of $T$. triandra extracts were performed by resazurine microplate assay (REMA) and tested with 3 cell lines: oral cavity cancer (KB), lung cancer (NCI-H187) and breast cancer (MCF-7) cell lines. ${ }^{11}$ In brief, cells $\left(5 \times 10^{3}\right.$ cells $\left./ \mathrm{mL}\right)$ were seeded on 96 -well plates and cultured in a culture medium containing $10 \%$ fetal bovine serum at $37^{\circ} \mathrm{C}$ for $24 \mathrm{~h}$. The medium was then replaced with serum-free medium containing the herbal extracts at various concentrations $(0,0.5,5$ and $50 /$ $\mathrm{mL}$ ). After incubation for $24 \mathrm{hrs}$ at $37^{\circ} \mathrm{C}$ under $5 \% \mathrm{CO}_{2}$, the supernatant was removed and the MTT solution $(0.5 \mathrm{mg} / \mathrm{mL})$ was added to each well at $4 \mathrm{hrs}$ prior to the end of the experiment. The formazan crystals that had formed in viable cells were measured using a wavelength of $540 \mathrm{~nm}$ in a spectrophotometer. All experiments were done in triplicate. The average data from the triplicates were expressed in terms of killing percentage relative to a negative control. The percentage of inhibition (\%) of each of the test samples was calculated according to the following formula:

$$
\text { Percentage of inhibition }(\%)=\left[\left(A_{\text {control }}-A_{\text {sample }}\right) / A_{\text {control }}\right] \times 100
$$

Cytotoxicity of each sample was calculated as $\mathrm{IC}_{50}$ value. The $\mathrm{IC}_{50}$ value is the concentration of the test compounds that cause $50 \%$ inhibition or cell death and was obtained by plotting the percentage inhibition versus concentration of the test compounds.

\section{RESULTS AND DICUSSION}

\section{Isolation and structure elucidation of the isolate compound}

The chemical component was isolated from the methanol extract of $T$. triandra leaves by chromatographic separation on a Silica gel column. It appeared as yellowish amorphous crystal. The IR spectrum revealed

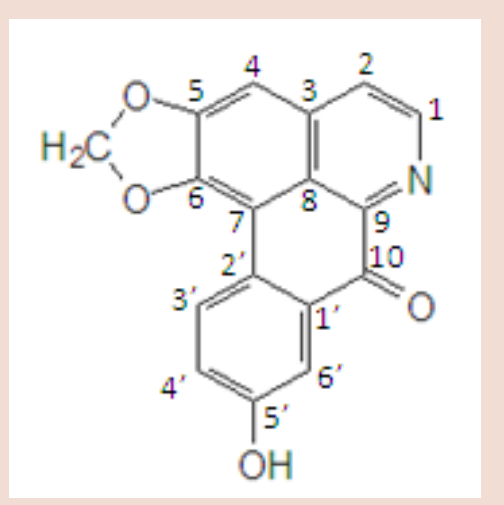

Figure 1: Structure of the isolated compound, Oxoanolobine

the vibration of the hydroxyl stretching $(-\mathrm{OH})$ at $3367 \mathrm{~cm}^{-1}$ (broad), carbonyl stretching $(\mathrm{C}=\mathrm{O})$ at $1621 \mathrm{~cm}^{-1}$. The electron impact mass spectrometry (EI-MS) showed molecular peak at $\mathrm{m} / \mathrm{z} 291$ which is in accordance with the structural formular of $\mathrm{C}_{17} \mathrm{H}_{9} \mathrm{O}_{4} \mathrm{~N}$. The ${ }^{13} \mathrm{C}$-NMR spectrum exhibited 17 signals (Table 1), together with the information from a DEPT spectrum, corresponding to 1 methylene, 6 methines, and 10 quaternary carbons. In the ${ }^{13} \mathrm{C}$-NMR spectrum data afforded 17 lines. The downfield region signal at $\delta 182.16 \mathrm{ppm}$ was in consistent with a carbonyl group while the resonance signals at $\delta 164.58$ and 164.29 ppm were assigned to the chemical shift of oxygen-bearing carbons of C-2 and C-6, respectively. The carbon signal at 161.47 was assigned to a nitrogen-bearing methylene (C-9) on the basis of a DEPT experiment and its chemical-shift value. The other carbon resonances were in accordance with those assignments reported with a known alkaloid, oxoanolobine. ${ }^{12}$ The ${ }^{1} \mathrm{H}-\mathrm{NMR}\left(500 \mathrm{MHz}, \mathrm{CD}_{3} \mathrm{OD}\right.$ ) signals (Table 1) for the compound were assigned by comparing the NMR spectral data with those of oxoanolobine. The ${ }^{1} \mathrm{H}-\mathrm{NMR}$ spectrum showed signals between $7.20-8.80 \mathrm{ppm}$ indicating the presence of aromatic protons. The singlet peak at $6.17 \mathrm{ppm}$ was assigned to two methyl group protons of oxygen bearing carbons. From these data, the structure of the isolated compound was assigned as oxoanolobine (Figure 1). This is the first report to show that oxoanolobine is the major constituent in T. triandra leaves.

\section{In vitro anticancer assay}

The anticancer activity of the herbal extracts and the isolated compound is shown in Table 2. The methanol extract and the water extract showed potent activity against oral cavity cancer (KB) and lung cancer (NCIH187), respectively, whereas the petroleum ether and the dichloromethane extracts appeared to be inactive in all human cancer $\left(\mathrm{IC}_{50}>50 \mu \mathrm{g}\right.$ $/ \mathrm{mL}$ ). Oxonanolobine possessed moderate activity against NCI-H187 with $\mathrm{IC}_{50}$ value of $27.6 \pm 4.30 \mu \mathrm{g} / \mathrm{ml}$ when compared to the standard anticancer drugs, doxorubicin and ellipticine. Previous study showed that alkaloids exhibited the cytotoxic activity against human lung cell lines. ${ }^{13}$ In addition, the results confirm the potential use of this plant for the treatment of cancer in traditional medicine reported by Nanasombat, $\mathrm{S}$ and Teckchuen, N. ${ }^{1}$

\section{CONCLUSION}

The present study showed that oxoanolobine was the main bioactive compound found in T. triandra leaves. The methanol extract showed the highest cytotoxic activity against lung cancer (NCI-H187) cell line whereas the water extract exhibited the highest activity against oral cavity cancer $(\mathrm{KB})$ when compared to the other extracts. The study indicated that $T$. triandra leaves might be applicable in natural medicine for cancer prevention and or treatment. 
Table 2: IC $\mathrm{C}_{50}$ value of the herbal extracts and the isolated compound against three cancer cell lines

\begin{tabular}{cccc}
\hline \multirow{2}{*}{ Extracts/compounds } & \multicolumn{3}{c}{ Cell lines $\left(\mathrm{IC}_{50^{\prime}} \mu \mathrm{g} / \mathrm{mL}\right)^{\mathrm{a}}$} \\
& $\mathrm{KB}$ & $\mathrm{NCl}-\mathrm{H} 187$ & MCF7 \\
\hline Petroleum ether & $>50$ & $>50$ & $>50$ \\
Dichloromethane & $>50$ & $>50$ & $>50$ \\
Ethyl acetate & $15.81 \pm 6.50$ & $33.38 \pm 11.07$ & $>50$ \\
Methanol & $32.15 \pm 10.94$ & $11.93 \pm 4.52$ & $>50$ \\
Water & $12.06 \pm 0.84$ & $12.27 \pm 2.98$ & $>50$ \\
Oxoanolobine & $>50$ & $27.6 \pm 4.30$ & $>50$ \\
Doxorubicin & $0.16 \pm 0.02$ & $0.06 \pm 0.00$ & $5.56 \pm 0.02$ \\
Ellipticine & $0.44 \pm 0.13$ & $1.16 \pm 0.10$ & $7.37 \pm 0.01$ \\
\hline
\end{tabular}

${ }^{\text {a}}$ The extracts with an $\mathrm{IC}_{50}$ value of $>50 \mu \mathrm{g} / \mathrm{mL}$ were considered inactive.

\section{ACKNOWLEDGEMENTS}

We would like to thank Mahasarakham University Fund and Faculty of Pharmacy, Mahasarakham University Fund for financial supports. The Bioassay Research Facility of BIOTEC (Thailand) is also acknowledged for the cytotoxicity tests.

\section{ABBREVIATIONS USED}

DEPT: Distortionless enhancement by polarization transfer, TLC: Thin layer chromatography, $\mathbf{I C}_{50}$ : Inhibitory concentration $50 \%$, IR: Infrared spectroscopy, MS: Mass spectrometry, MTT: 3-(4,5-dimethylthiazol2-yl)-2,5-diphenyltetrazolium bromide, NMR: Nuclear magnetic resonance, REMA: Resazurin microplate assay.

\section{REFERENCES}

1. Nanasombat S, Teckchuen N. Antimicrobial, antioxidant and anticancer activities of Thai local vegetables. J. Med. Plants Res. 2009; 3(5): 443-9.

2. Katchrinnee P, Webstar HK, Yongvanitchit K, Dechatiwongse T. Antimalarial activity of Tiliacora triandra Diels against Plasmodium falciparum in vitro. Phytother Res. 2006; 30(5): 215-7.

3. Gutirrez RMP. Handbook of compounds with cytotoxicity isolated from plants. Nova Sciences Publishers, New York, United State of America; 2007.

4. Singthong J, Ningsanond S, Cui SW. Extraction and physicochemical characteri- sation of polysaccharide gum from Yanang Tiliacora triandra leaves. Food Chem 2009; 114(4): 1301-7.

5. Wiriyachitra P, Blackwell BA. Alkaloids of Tiliacora triandra. Aust J Chem. 1981; 34(9): 2001-4.

6. Sireeratawong S, Lertprasertsuke N, Srisawat U, Thuppia A, Ngamjariyawat A, Suwanlikhid N, et al. Acute and subchronic toxicity study of the water extract from Tiliacora triandra (Colebr.) Diels in rats. Songklanakarin J. Sci. Technol. 2008; 30(1): 611-9.

7. World Health Organization. National cancer control programmes: Policies and managerial guidelines, Geneva; 2002.

8. Ahmedin J, Melissa MC, Carol D, Elizabeth MW. Global patterns of cancer incidence and mortality rates and trends. Cancer Epidem Biomar. 2010; 19(8): 1893-907.

9. Hung HC, Joshipura KJ, Jiang R, Hu FB, Hunter D, Smith-Warner SA, et al. Fruit and vegetable intake and risk of major chronic disease. J Natl Cancer Inst. 2004; 96(21): 1577-84.

10. World Health Organization Diet. Nutrition and prevention of chronic disease World Health Organization. Geneva; 2003.

11. Skenhan P, Stroren R, Scudiero D, Monks A, Mcmahon J, Vistica D, et al. New colorimetric cytotoxicity assay for anticancer-drug screening. J Natl Cancer Inst. 1990; 82(13): 1107-12.

12. Payakarintarungkul K. Antioxidants from Uvaria rufa Blume roots. Chulalongkorn University, Bangkok; 2005.

13. Wada K, Hazawa M, Takahashi K, Mori T, Kawahara N, Kashiwakura I. Structure-activity relationships and the cytotoxic effects of novel diterpenoid alkaloid derivatives against A549 human lung carcinoma cells. J Nat Med. 2011 65(1): 43-9.
PICTORIAL ABSTRACT

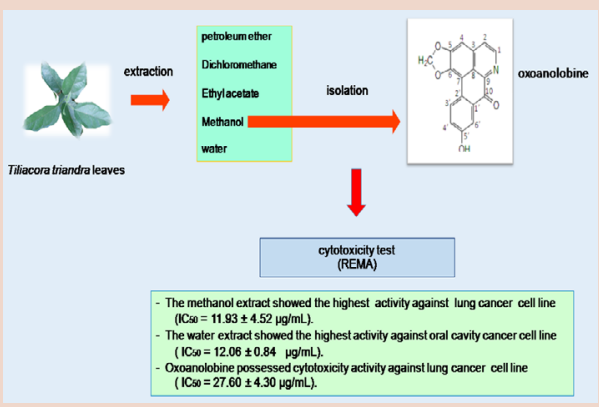

\section{SUMMARY}

- The methanol extract of Tiliacora triandra leaves showed the highest cytotoxic activity against lung cancer ( $\mathrm{NCl}-\mathrm{H} 187)$ cell line whereas the water extract exhibited the highest activity against oral cavity cancer (KB) cell line with $I_{50}$ values of $11.93 \pm 4.52 \mu \mathrm{g} / \mathrm{mL}$ and $12.06 \pm 0.84 \mu \mathrm{g} / \mathrm{mL}$, respectively.

- The main chemical constituent of the methanol extract is oxoanolobine.

- Oxoanolobine possessed cytotoxicity activity against lung cancer cell line with $\mathrm{IC}_{50}$ of $27.60 \pm 4.30 \mu \mathrm{g} / \mathrm{mL}$.

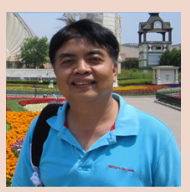

\section{ABOUT AUTHOR}

Dr. Methin Phadungkit (Ph.D): Is an Assistant Professor of the Faculty of Pharmacy, Mahasarakham University, Thailand. His research fields include natural products chemistry, biological activity testing as well as development of dosage forms of natural products. His researches focus on phytochemistry and biological activity testing of natural products. 